\title{
A Recognition System of Hand Written Hangeul Considering Stroke Order
}

\author{
*Jeong-Young SONG, *Kageo AKIZUKI, †Hee-Hyol LEE \\ *Akizuki Laboratory, Dept. of Electrical Engineering, Waseda university, 3-4-1 \\ Ohkubo, Shinjuku-ku, Tokyo, 169 JAPAN \\ $\nmid$ Faculty of Engineering, Fukuoka Institute of Technology 3-30-1 Wajirohigashi, \\ Higashi-ku, Fukuoka, 811-02 JAPAN
}

\section{$<$ ABSTRACT $>$}

This paper describes how to recognize hand written Hangeul character using the stroke order of the elementary segment.

The recognition system is constructed of 4 parts: character input part, segment disassembling part, character element extraction part and character recognition part.

The character input part reads the character and performs thinning algorithm. In the segment disassembling part, the input character is disassembled into elementary segments using the direction codes and the feature parameters. In the character element extraction part, we extract the character element using the stroke order and the knowledge rule. Finally, we are able to recognize the hand written Hangeul characters by assembling the character elements, in the character recognition part.

\section{INTRODUCTION}

Hangeul characters are composed of 14 consonants and 10 vowels as the basic character elements. Each of the character element is assembled from the following 7 kinds of the elementary segments.

- / ; LI(Left-Inclination)

- $\backslash ; \mathrm{RI}$ (Right-Inclination)

- - ; LR(Left-Right)

- 1 ; UD(Up-Down)

- $\cap, 0 ; \mathrm{C}($ Circle $)$

- 7,7 ; RD(Right-Down)

- L,v;DR(Down-Right)
Furthermore, the segments are generated from combination of the basic strokes $(/, 1,1,-, 0)$.

Considering the foregoing special features of Hangeul, a hand written Hangeul character recognition system is proposed in this paper. The system takes into account of the stroke order of the elementary segments. The flow of the recognition procedure is shown in Fig. 1.

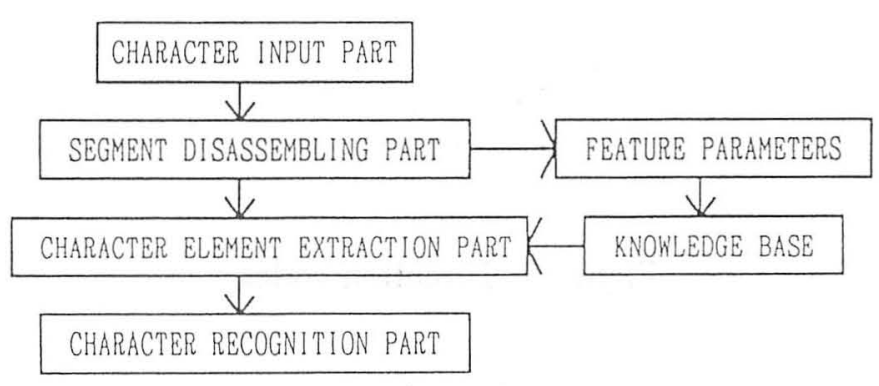

Figure 1: Recognition procedure

\section{CHARACTER INPUT PART}

A hand written Hangeul character is read by a camera and transformed to 82 by 82 white and black points. We perform the centering of the character and thinning process as a preprocessing. For example, the hand written charcter KIM' 김' after the preprocessing is shown in Fig. 2. The numbers written in the character are the stroke order of the elementary segment.

\section{SEGMENT DISASSEMBLING PART}

In this part, Hangeul characters are disassembled into the 7 elementary segments. The elementary segments are found by the following 


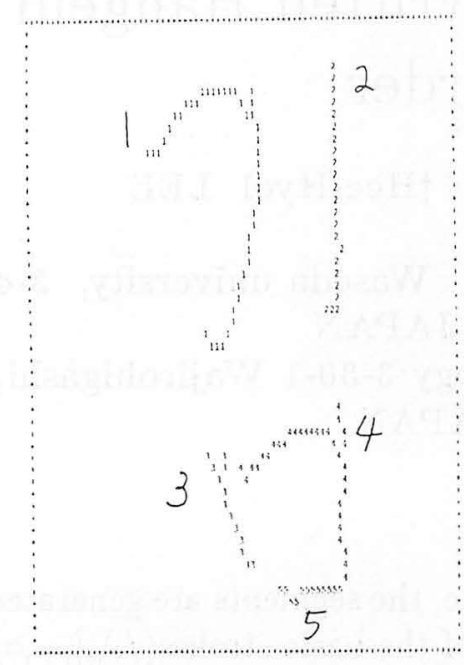

'KIM'

Figure 2: An example of input character (After the preprocessing)

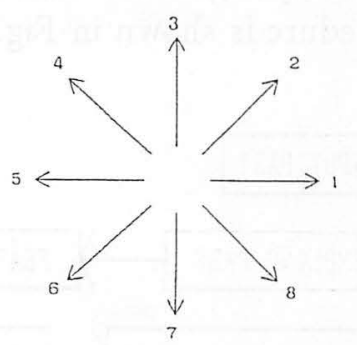

Figure 3: Direction codes

procedure. In the first place, we detect starting point of the stroke by searching from the upper-left corner. From the starting point and next point, we identify the direction codes shown in Fig. 3. The stroke is determined from the number of the series of the same direction code. When the point number is smaller than 10, it is rejected as a noise. After go through these steps, we extract the feature parameters ; starting coordinates, ending coordinates, length of stroke and angle of stroke. And by following to the flow-chart in Fig. 4, we extract feature parameters. These parameters are stored into knowledge base. And then, the input character is disassembled to the elementary segments by the rule shown in Table 1.

As an example of the UD, IF the series of the same directionn code greater than 10 and the angle of the stroke is between 70 and 100 degrees
THEN this storke is UD.

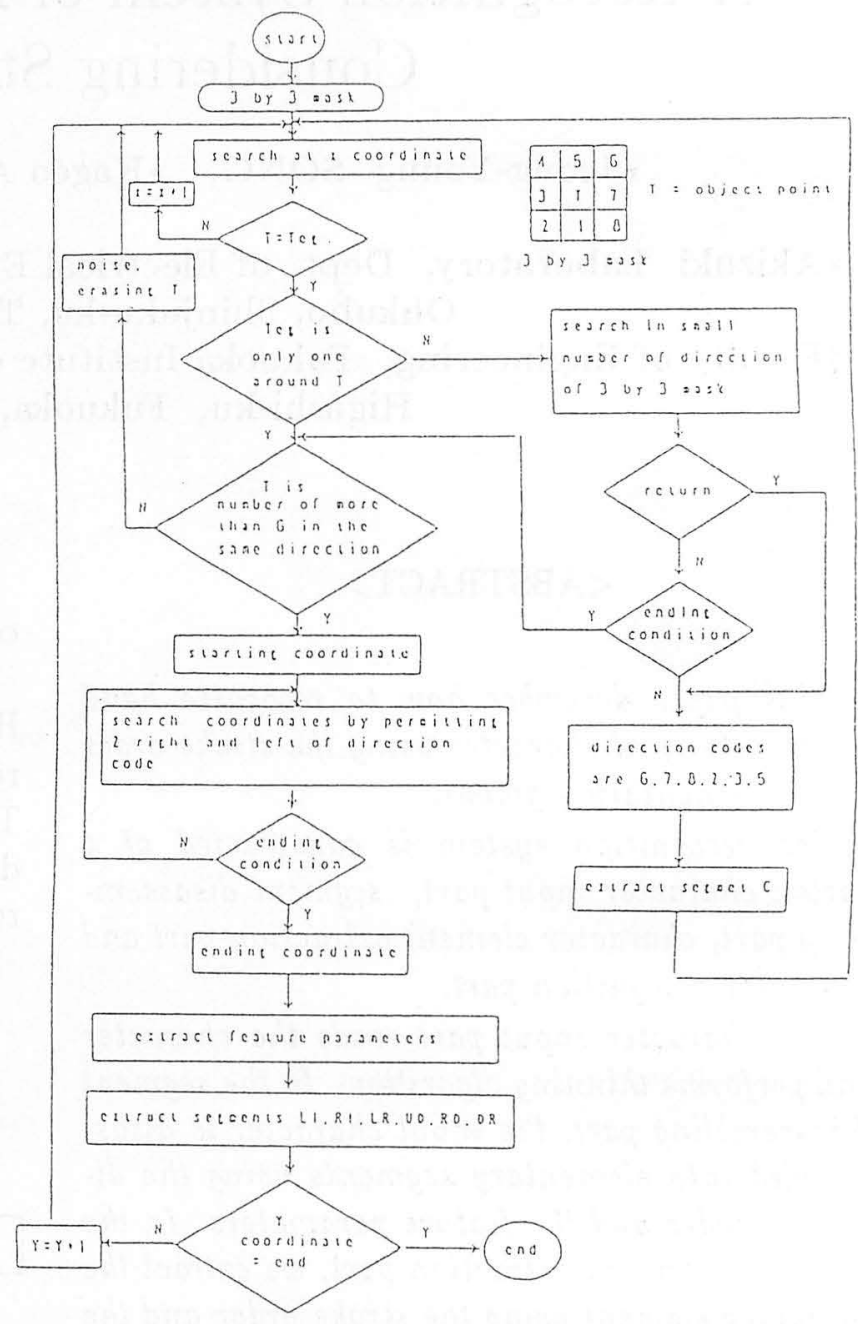

Figure 4: Flow-chart of extraction of the feature parameters

\begin{tabular}{|c|c|c|}
\hline & $\begin{array}{l}\text { The series of the same } \\
\text { direction code greater than } 10\end{array}$ & The angle of the stroke \\
\hline LI & 6 & $40^{\circ} \sim 70^{\circ}$ \\
\hline RI & 8 & $110^{\circ} \sim 140^{\circ}$ \\
\hline$L R$ & 1 & $170^{\circ} \sim 210^{\circ}$ \\
\hline UD & 7 & $70^{\circ} \sim 100^{\circ}$ \\
\hline$C$ & $6,7,8,2,3,5$ & $250^{\circ} \sim 360^{\circ}$ \\
\hline \multirow{4}{*}{ RD } & \multirow{2}{*}{ 1. 7} & $170^{\circ} \sim 210^{\circ}$ \\
\hline & & $70^{\circ} \sim 100^{\circ}$ \\
\hline & \multirow{2}{*}{ 1. 6} & $170^{\circ} \sim 210^{\circ}$ \\
\hline & & $40^{\circ} \sim 70^{\circ}$ \\
\hline \multirow{4}{*}{$D R$} & \multirow{2}{*}{7,1} & $70^{\circ} \sim 100^{\circ}$ \\
\hline & & $1.70^{\circ} \sim 210^{\circ}$ \\
\hline & \multirow{2}{*}{$7 \cdot 2$} & $70^{\circ} \sim 100^{\circ}$ \\
\hline & & $210^{\circ} \sim 240^{\circ}$ \\
\hline
\end{tabular}

Table 1: The rules of elementary segments

The feature parameters of the input character HONG'㐔' and the extracted segments are shown 
Fig. 5 as example. Where \# is the number of the stroke order, $\mathrm{X} 0$ and $\mathrm{Y} 0$ are the starting coordinates, $\mathrm{X} 1$ and $\mathrm{Y} 1$ are the ending coordinates, $\mathrm{L}$ is the length of the stroke and THE is the inclination of the stroke respectively. And we define the length of a circle as zero.

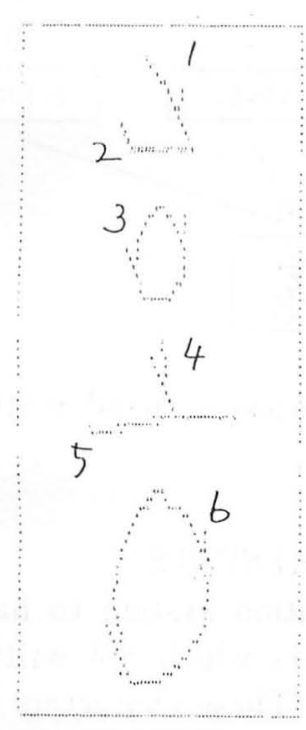

'HONG'
Information of kakijun 1

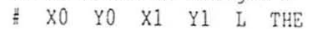
$\begin{array}{lllllll}1 & 5 & 36 & 16 & 49 & 17 & 139\end{array}$ RIGHT-INCLINATION RI Information of kakijun 2

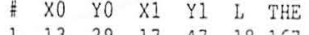
$\begin{array}{lllllll}1 & 13 & 29 & 17 & 47 & 18 & 167\end{array}$ RIGHT-INCLINATION RI Information of kakijun 3 \# XO $\quad Y_{0} \quad X_{1} \quad Y_{1} \quad$ L $\quad$ THE $\begin{array}{lllllll}1 & 23 & 39 & 23 & 39 & 0 & 360\end{array}$ CIRCLE C

Information of kakijun 4

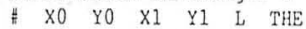
$\begin{array}{lllllll}1 & 39 & 41 & 48 & 44 & 9 & 108\end{array}$ UP-DOWN UD

Information of kakijun 5 \# XO YO XI YI L THE $\begin{array}{lllllll}1 & 49 & 40 & 49 & 61 & 21 & 180\end{array}$ LEET-RIGHT LR

Information of kakijun 6

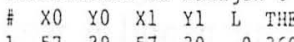
$\begin{array}{lllllll}1 & 57 & 39 & 57 & 39 & 0 & 360 \\ \text { CIRCLE } & C & & & \end{array}$

Figure 5: An example of the feature parameters and elementary segments of HONG' $\frac{\dot{s}}{0}$ '

\section{CHARACTER ELEMENT EXTRAC- TION PART}

In this part, the character element is extracted by the procedure shown in Fig. 6 .

In this procedure, the number of the segments starts from the 4 segments, because a character elements of Hangeul gets 4 segments as its maximum.

The order of the segments in writing Hangeul character is shown in Table 2.

On the other hand, some segments have same stroke order as the other, such as the vowels ' $\perp$ ' and ' $\vdash$ ' have UD, LR stroke order. For these we apply the elements knowledge base.

Other Hangeul character vowels which have the knowledge base are shown in Table 3. Where superscripts of feature parameters $X$ and $Y$ are the stroke order of the elementary segment. The subscripts are the starting coordinates.

Another example is the knowledge rules for consonant character elements' $\forall$ ' and 'II' as

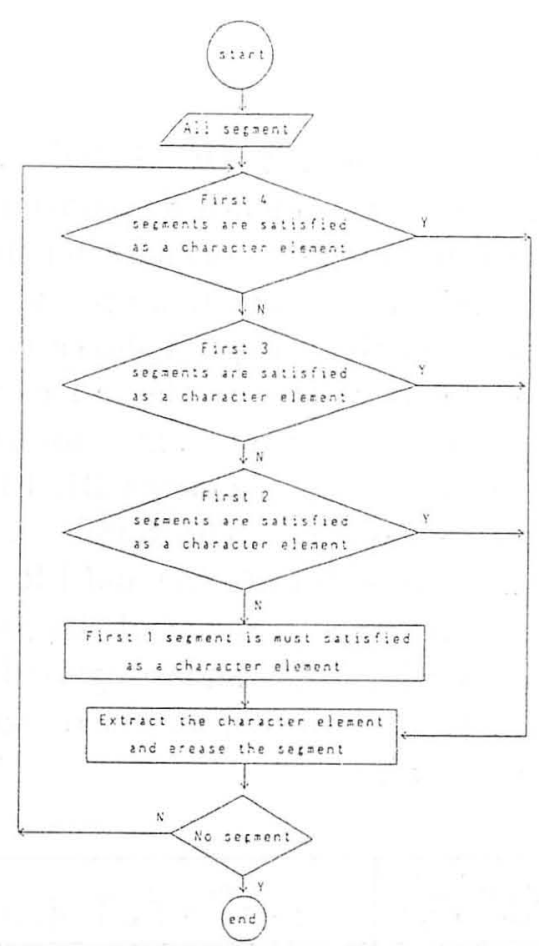

Figure 6: The procedure of character elements extraction

shown in Fig. 7.

\begin{tabular}{|c|c|c|c|c|}
\hline$V$ & $\begin{array}{l}\text { The first } \\
\text { segment }\end{array}$ & $\begin{array}{c}\text { The second } \\
\text { segment }\end{array}$ & $\begin{array}{l}\text { The third } \\
\text { segment }\end{array}$ & $\begin{array}{l}\text { The fourth } \\
\text { segment }\end{array}$ \\
\hline 7 & $R D$ & * & * & * \\
\hline$L$ & $\mathrm{DR}$ & $*$ & $*$ & $*$ \\
\hline$E$ & $L R, L !$ & $D R$ & * & $*$ \\
\hline 己 & RD & LR, LI & $\mathrm{DR}$ & $*$ \\
\hline 므 & UD, RI & $R D$ & LR, LI & $*$ \\
\hline $\mathrm{H}$ & UD & UD & $L R$ & LR \\
\hline 人 & L! & RI & * & $*$ \\
\hline 0 & $\mathrm{C}$ & * & * & $*$ \\
\hline$\pi$ & $R D$ & $R I$ & $*$ & $*$ \\
\hline $\bar{\lambda}$ & $L R, U D, L I$ & RD & $R !$ & $*$ \\
\hline 7 & $R D$ & LR & $*$ & * \\
\hline$E$ & $L R, L I$ & $D R, L R, L I$ & LR, DR & * \\
\hline II & LR , LI & UD & UD & LR. . LI \\
\hline$\frac{1}{0}$ & $U D, L R, R !$ & $L R, R I$ & C & $*$ \\
\hline 1 & UD & LR . L! & * & * \\
\hline$F$ & UD & $L R, L I$ & LR, LI & $*$ \\
\hline-1 & $L R, L !$ & UD & * & * \\
\hline$=1$ & LR , LI & LR, LI & UD & * \\
\hline 1 & UD, R! & $L R, L I$ & $*$ & $*$ \\
\hline II & UD. R! & UD, RI & LR . L! & * \\
\hline$T$ & LR . LI & UD & * & * \\
\hline$\pi$ & LR , LI & UD & UD & * \\
\hline- & LR , LI & $\%$ & $*$ & $*$ \\
\hline 1 & UD & * & * & * \\
\hline$=11$ & LR. LI & $L R, L I$ & UD & UD \\
\hline-11 & $L R, L !$ & $U D$ & UD & $*$ \\
\hline$H$ & UD & $L R, L I$ & UD & * \\
\hline
\end{tabular}

Table 2: The order of the segments when writing Hangeul character 


\section{CHARACTER RECOGNITION PART}

In this part, we recognize a character by assembling to the categories of character elements. As an example, the recognition process of hand written Hangeul HONG' 홍' is shown in Fig. 8. This character is written in the order of consonant, vowel and consonant. The consonant ' $\overline{\text { ' }}$ is disassembled to the segments RI, RI and C and recognized as ' $\overline{0}$ '. The vowel ' $\perp$ ' is disassembled to the segments UD and LR and recognized as ' $\perp$ '. The segment of the consonant ' $O$ ' is disassembled to $C$ and recognized as ' $O$ '. Combining these elements, we can recognize the character as '言'.

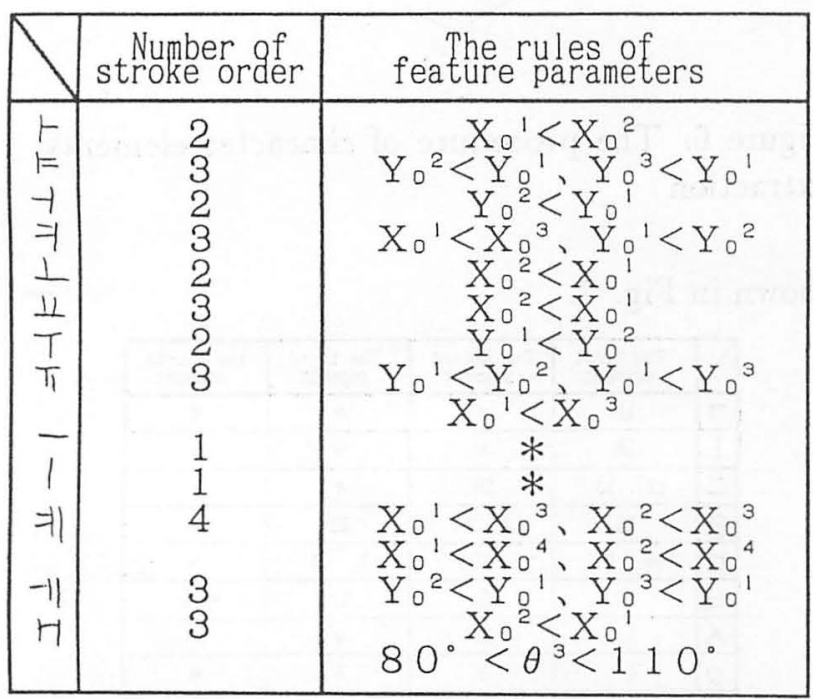

Table 3: Knowledge base of the vowels

$$
\begin{aligned}
& \operatorname{IF}\{(\text { the first segment }=U D \text {. and. } \\
& \text { the second segment }=U D \text {. and. } \\
& \text { the third segment }=L R \text {. and. } \\
& \text { the fourth segment }=L R) \text {. AND. } \\
& \left(Y_{0}{ }^{1}<Y_{0}{ }^{3}<Y_{0}^{4} \text {. and. } X_{0}{ }^{2}>X_{0}{ }^{1}\right. \text {. and. } \\
& \text { THEN } \\
& \left.\left.70^{\circ}<\theta^{\prime}<100^{\circ} \text {. and. } 70^{\circ}<\dot{\theta}^{2}<100^{\circ}\right)\right\} \\
& \operatorname{IF}\{((\text { the firth segment }=L R \text { or } R I) \text {. and. } \\
& \text { the second segment }=U D \text {. and. } \\
& \text { the third segment }=U D \text {. and. } \\
& \text { ( the fourth segment }=L R \text { or } R I) \text { ). AND. } \\
& \left(X_{0}{ }^{1}<X_{0}{ }^{2}<X_{0}{ }^{3} \text {. and. } X_{0}{ }^{3}>X_{0}{ }^{2}\right. \text {. and. } \\
& \text { THEN ' } I 0^{\circ} \text { ' } \\
& \left.\left.70^{\circ}, I^{\prime}, \theta^{2}<100^{\circ} \text {. and. } 70^{\circ}<\theta^{3}<100^{\circ}\right)\right\}
\end{aligned}
$$

Figure 7: Knowledge rules for character elements' $\forall$ ' and 'II'

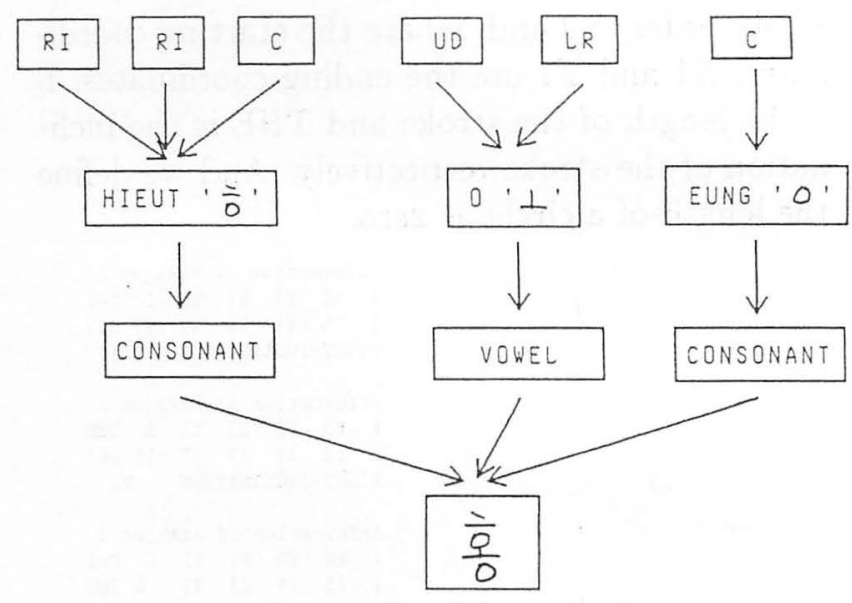

Figure 8: Recognizing process of hand written Hangeul ' $\frac{\bar{s}}{0}$ '

\section{EXPERIMENTAL RESULTS}

We applied our recognition system to hand written Hangeul characters which are written by 7 men and 6 women. These characters are the names randomly taken from "Korean Spiritual and Cultural Institute" which is the Korean standard name book. In this experiment, 95.3 percent of 280 characters are recognized correctly. The examples succeeded in recognition are shown in Fig. 9.

Some of the mistakes come from the segment disassembling part, because their character elements are connected each other.

The examples of fail in recognition are shown in Fig. 10.

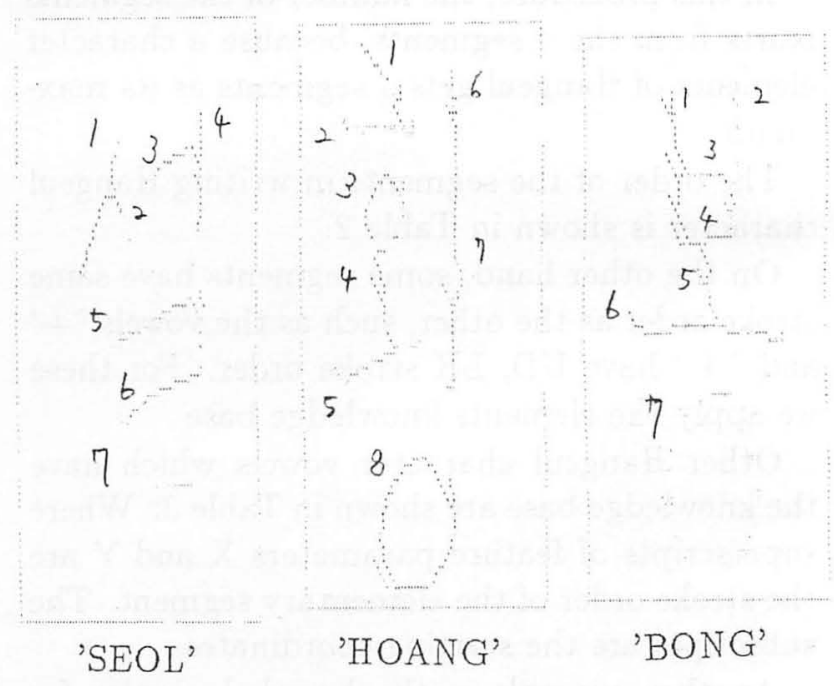

Figure 9: Patterns succeeded in recognition 


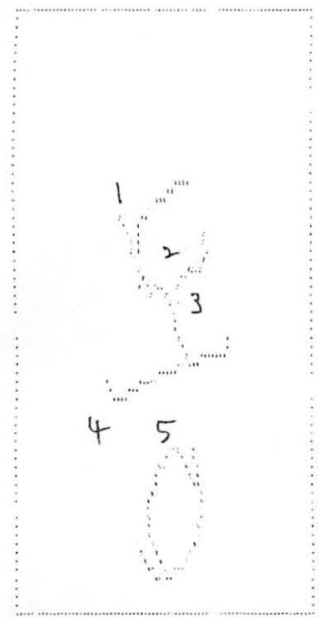

'DONG'

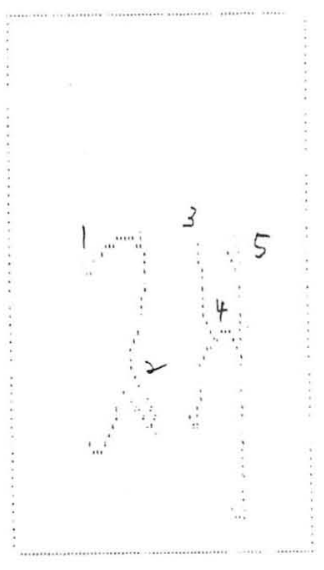

'JAE'

Figure 10: Patterns failed in recognition

\section{CONCLUSION}

In this paper, we propose a recognition system of hand written Hangeul which takes into account the stroke order of the elementary segments. The effect of this recognition method was confirmed by experimental studies. Now, we are improving the systems to recognize a character in running style.

\section{REFERENCES}

(1) J.Y.Song, H.H.Lee, W.K.Choi, K.Akizuki, A Recognition of Hand Written Hangul by Structure Information, pp.715-716, SICE'92.

(2) J.Y.Song, H.H.Lee, W.K.Choi, K.Akizuki, Recognition of Hangul in a Simplied Form, pp.21-24, ISCIE 1992.

(3) J.Y.Song, H.H.Lee, W.K.Choi, K.Akizuki, A Recognition of Hand Written Hangul by Fuzzy Valuation of Segment, T.IEE Japan, Vol.113-C, No.4, '93.

(4) J.Y.Song, H.H.Lee, W.K.Choi, K.Akizuki, Recognition of Hand Written Hangul by the Back Propagation Algorithm with Moment Method, ISCIE, 1993. 
